\title{
Experimental study on spray characteristics of diesel-FAME blends
}

\author{
Yijun Zhang1, Wenfu Liu' ${ }^{2}$, Di Zhu ${ }^{3}$ \\ Henan Vocational College of Agriculture, Henan Zhengzhou, 451450, China \\ ${ }^{1}$ Corresponding author \\ E-mail: ${ }^{1}$ zhangjun_003@126.com, ${ }^{2}$ liuwenfu@163.com, ${ }^{3}$ zhudi@126.com \\ Received 28 January 2021; received in revised form 10 February 2021; accepted 15 February 2021 \\ DOI https://doi.org/10.21595/vp.2021.21893
}

Check for updates

Copyright (C) 2021 Yijun Zhang, et al. This is an open access article distributed under the Creative Commons Attribution License, which permits unrestricted use, distribution, and reproduction in any medium, provided the original work is properly cited.

\begin{abstract}
Macro-spray structural parameters and micro-droplet of diesel-FAME under the circumstance of different FAME content, injection pressure and nozzle diameter were studied. With the increase of FAME content, the spray penetration increases, and spray angle decreases, molecules viscous force and the micro-droplet size increase, which means the atomization getting worse. With the increases of injection pressure, the penetration increases, the spray angle decreases. The more FAME content, the greater the rate of them. The microscopic droplet size decreases as pressure increasing. With increased nozzle diameter, the cavitations of liquid become weak, the penetration extends, and the spray angle decreases. Droplet size becomes bigger and atomization gets worse.
\end{abstract}

Keywords: FAME, spray characteristic, injection pressure, nozzle diameter.

\section{Introduction}

Bio-diesel can be obtained by transesterification from animal or vegetable fats with methanol. It is mixed fatty acid methyl esters namely FAME [1]. FAME is new and renewable energy. Since the production of different materials or preparation process, FAME has high kinematic viscosity, density and surface tension compared to regular diesel fuel. Being clean properties, FAME often is mixed with diesel as a certain ratio. In order to meet national fuel standards, the perfect FAME content of the mixed fuel must be chosen [2]. The paper showed that the conversion of a car with a gasoline engine to LPG leads to a reduction in fuel consumption, expressed in thermal equivalent, by $10 \%$. The values of mass emissions of carbon monoxide per cycle are almost the same for both fuels. Emissions of hydrocarbons from LPG increased from 0.035 to $0.183 \mathrm{~g} / \mathrm{km}$, and of nitrogen oxides from 0.142 to $0.233 \mathrm{~g} / \mathrm{km}$. Mass emissions of carbon dioxide when powering the car LPG decreased from 217.8 to $177.9 \mathrm{~g} / \mathrm{km} \mathrm{[3].}$

Atomization of the fuel is that large liquid column or liquid film becomes small droplets. From the perspective of the force, atomization process can be seen as the process of the joint function between the external forces and internal to be torn [4]. Firstly, the air force (external force) on the liquid surface makes liquid column split. Secondly, the liquid molecules, i.e., the gravitational force attempting to maintain its original viscosity shape. The third factor is that surface tension of the liquid forces it to form a small sphere, the liquid preserving a minimum surface energy. When the external force is greater than the surface tension of the liquid and the liquid inside the viscous force, atomization will happen $[5,6]$.

In this paper, factors the effects of internal and external forces of the fuel molecules had been studied, including fuel quality, injection pressure, environmental pressures and the parameter of the injector nozzle. Spray characteristics under different environmental pressures, injection pressures, nozzle diameter and different mixing ratio had been analyzed, which provided a basis for the practical application of FAME (meaning of FAME is Fatty Acid Methyl Ester).

\section{Materials}

Test equipment including high pressure pump, constant volume combustion devices, signal 
generator controller and high pressure injector. The principle of the test system is shown in Fig. 1. Constant volume combustion simulated the engine cylinder. The high-pressure nitrogen control inner environmental pressures of the constant volume. For the sake of easy display color difference, the inner wall of the adjacent sides was decorated with black screens [7]. The remaining two walls were pressure- glass window, one used as through into the light, another taking photography. Test fuel was mixtures of biodiesel from waste oil and 0\# diesel.

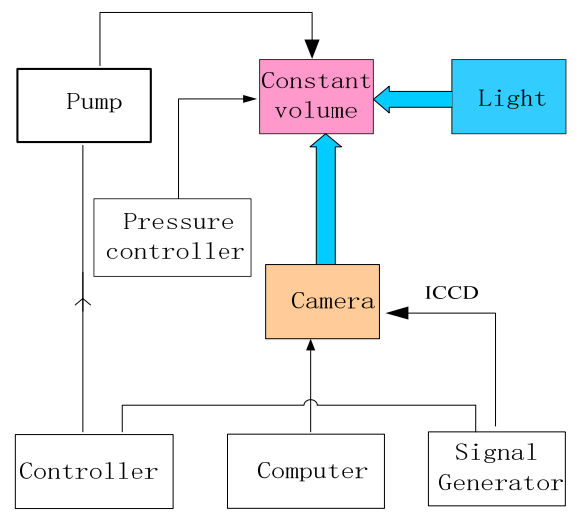

Fig. 1. Schematic spray test device

\section{Analysis methods}

\subsection{Macro analysis}

Spray penetration is distance along the axial direction from the nozzle spray holes. The penetration reflected the maximum exercise capacity of liquid out of the inertial forces and surface tension. Spray cone angle was also called atomized angle, which referred to the angle between the tangent export injector spray oil and the outer envelope of the two beams. Spray angle could be measured with the size of fuel atomization divergence. The greater the fuel cone angle, the larger the divergence [8-10]. As Fig. 2 showed, the spray mist is axis symmetrical, spray angle $\alpha$ was following:

$\alpha=2 \arctan \frac{D}{2 L}$.

Because the angle was not limited by length of the unit, length of $D, L$ can be determined directly by measuring the parameters of the pixel image.

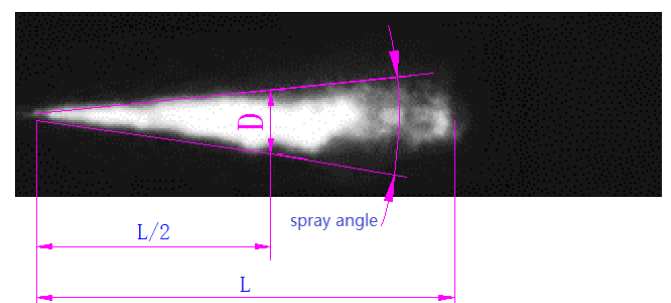

Fig. 2. Definition of penetration and spray angle

\subsection{Micro analysis}

Microscopic analysis studied spray droplet size and number of a certain range. Through software Matlab and Photoshop processing images, which were intuitively clear expression of the 
distribution and could gain more accurately microscopic droplets.

(1) Conversion between image pixel and length meter.

Along the axis direction of the nozzle, 10 um diameter inelastic $t$ wire was pulled and its image was captured with the camera, which aimed at the relationship between the length and the calibration pixel. Thus, droplet diameter would be read approximately [11]. Preparation was that adjustment of camera focal length was done and fixed its position. Standard wire diameter was read through Photoshop software four pixels, so the length and pixel conversion factor are:

$\lambda=\frac{10 \mu \mathrm{m}}{4 \text { Pixel }}=2.5 \mu \mathrm{m} /$ Pixel.

(2) Statistical analysis of the droplets particle size.

Droplets distribution was analyzed by the number percentage of a certain diameter. Number of droplets in the diameter range of $\left(d_{i}-\frac{\Delta d_{i}}{2}\right)<d_{i}<\left(d_{i}+\frac{\Delta d_{i}}{2}\right)$ to the total number of droplets was the number distribution percentage of droplet certain diameter [12]. Horizontal axis referred to droplet diameter and the number percentage of the droplets was ordinates, then the distribution curve was drawn.

\subsection{Test program}

When the ratio of FAME was over $60 \%$, the density and viscosity of mixing fuel could be over the fuel standards. So, we have selected a mixed fuel of less than $60 \%$ FAME content as the samples for testing analysis. In order to make the more obvious effect, samples of BD0, BD20, $\mathrm{BD} 40, \mathrm{BD} 60$ and BD100 were selected to generate macro and micro characteristics analysis. Here, BD20 represent that FAME ratio was $20 \%$ and $0 \#$ diesel ratio was $80 \%$.

\section{Results and analysis}

\subsection{Impact of FAME ratio on macro-atomization characteristics}

Spray conditions had been set that the injector nozzle diameter was $0.25 \mathrm{~mm}$, injection pressure was $90 \mathrm{MPa}$, and the pressure in a constant volume chamber was $0.4 \mathrm{MPa}$. Distribution structure and spray droplet diameter of the four mixing fuel were studied and the results shown as Fig. 3 and Fig. 4.

Showing as Fig. 3, horizontal analysis, spray angle of each mixing fuel decreased with time, penetration of spraying rapidly grew at the initial stage, slowly at the mid-final stage of the trend stable, gas concentration was increased to the maximum, a faster transition process from small concentrations, and then gradually decreased from the maximum to the final concentration was almost zero, main reason was that fuel had just ejected from the nozzle when environmental gas heat exchange had taken. Thus, the temperature was close to the ambient temperature. The fuel energy was sufficient to evaporate the liquid from the gas, the phase concentration increased rapidly. With the development of a gas phase diffusion and evaporation of the ambient gas, the concentration of the gas had become smaller and smaller.

Longitudinal analysis, under the same conditions, the greater percentage of FAME, the smaller spray angle, and the spray atomization range decreases in the initial phase. As Concentration of FAME increased, the beam penetration of mixed fuel was gradually increased, and the more FAME contained, the longer fuel beam remained, which were mainly due to different kinematic viscosity, density and surface tension diesel between FAME and diesel, thus FAME had poor atomization performance. Larger proportion of FAME fuel of mixed fuel made atomization performance worse.

At the initial spray, the greater FAME content, the smaller spray angle and penetration, lately, the angle becomes smaller and smaller and penetration was longer and longer with the increase of 
the FAME content. The largest spray angle was $55^{\circ}$; the pure FAME spray angle was only $33^{\circ}$. As Fig. 3 shows, the increasing of FAME caused by the diffusion of mixed fuel molecules to reduce the capacity evaporation, fogging capabilities. Unable to overcome the initial spray of fuel molecules viscous damping force, FAME content is, the more obvious the damping effect, spray a small range.

BD0, BD30 and BD100 fog field microscopic images shown in Fig. 3. Spray image, from top to bottom, is the axial direction of the fuel spray. As can be seen, BD100 large droplets significantly more than large droplets BD0 from the point of view of both the apparent uniformity of the difference between the larger droplet broken, BD0 spray droplets and small particles uniformly, while pure biodiesel spray large significantly greater portion of the droplet and accompanied by droplet adhesion. These phenomena show that as many as FAME content illiquid, difficult broken droplets, spray uneven.

As can be observed in Fig. 4, distribution of the most droplet number was at $17.5 \mathrm{um}$. In the particle size range of less than $35 \mathrm{um}$, distribution curve of BD0 enveloping the other fuel samples', and with the increase in the content of FAME, larger than 35um diameter droplets increased.

That large particle droplets increased indicated deterioration of fuel atomization. Inside viscous force was too difficult to be destroyed by the external beam aerodynamic. The atomization quality of BD100 was the worst.

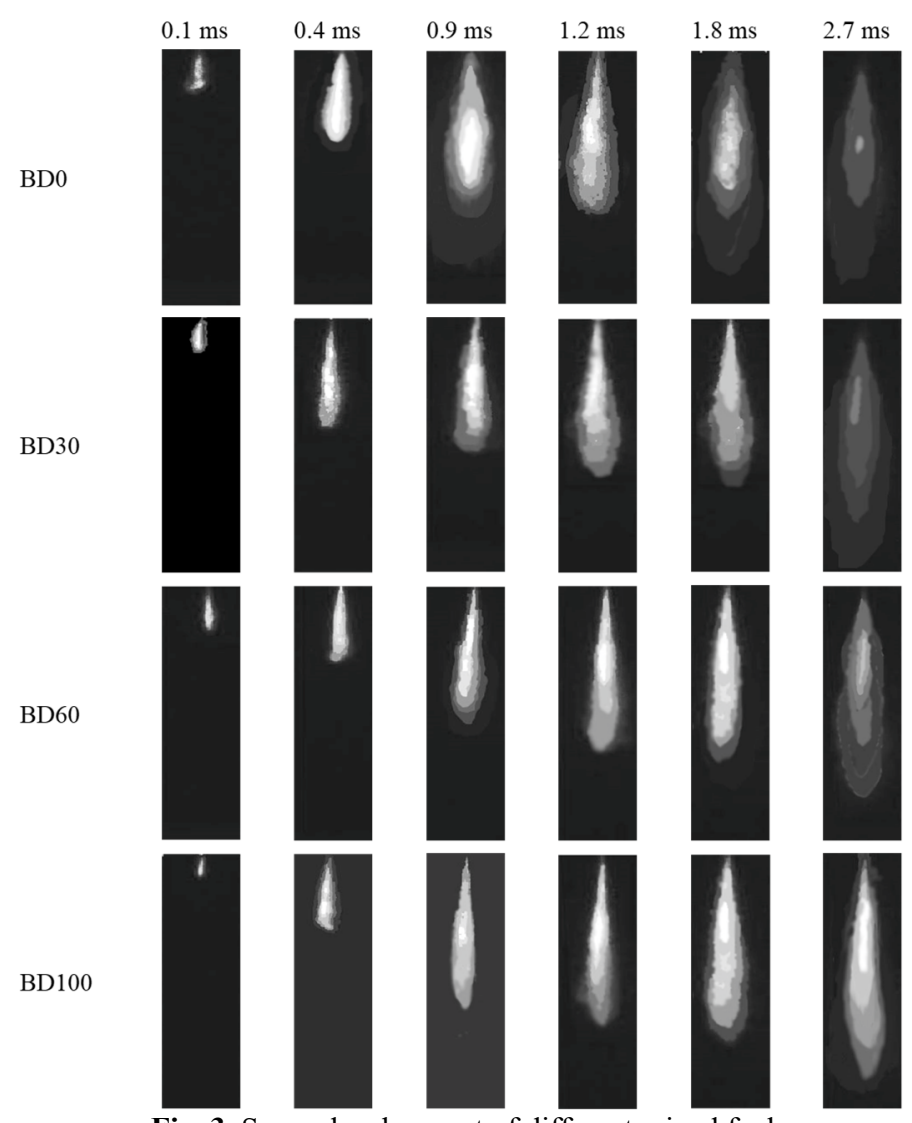

Fig. 3. Spray development of different mixed fuel

\subsection{Effect of injection pressure of the mixed fuel atomization characteristics}

Test conditions were same amount of a single injection per time, volume chamber pressure 
$4 \mathrm{MPa}$, nozzle diameter $0.25 \mathrm{~mm}$, and penetration was allowable range. Injection pressures were set to be $50 \mathrm{MPa}, 70 \mathrm{MPa}, 90 \mathrm{MPa}$ and $110 \mathrm{MPa}$, and then spray case was measured. Fig. 5 show the variation of penetration and the spray angle of BD30. With the injection pressure increasing, spray range increased, mainly due to the higher injection pressure, the larger initial kinetic energy that made the axis direction of movement longer. The smaller the injection pressure, the less initial kinetic energy could be obtained. Spray angle was increased with the injection pressure decreasing.

The main reason was the case that the higher injection pressure made the droplet have larger axial movement inertia.

As can be observed in Fig. 4, with the increasing of injection pressure, the increase rate of the spray range was faster. Namely, the greater content of FAME was, injection pressure was the greater influence on the spray range. Spray angle declined more steeply with the FAME content increasing. The diversifications of BD30 and BD20 were similar. Statistical analysis of BD30 at the time of $1.8 \mathrm{~ms}$ was shown as Fig. 6 . When injection pressure was $30 \mathrm{MPa}$, the number of large droplet bigger than 40 um was about $41.5 \%$. When the pressure was up to $90 \mathrm{MPa}$, small droplets, less than $30 \mathrm{um}$, were dominant and the number was more than $90 \%$. Droplet diameter of the other two pressures was between $30 \mathrm{MPa}$ and $90 \mathrm{MPa}$, and with increasing pressure, a small increase in large droplet droplets decreases. Thus, in the combustion chamber conditions allowed more conducive injection pressure fuel atomization.

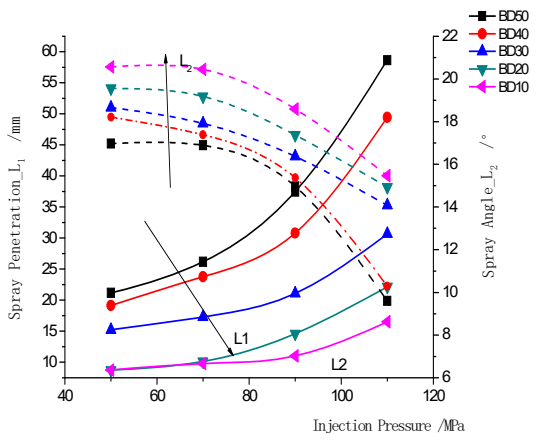

Fig. 4. Spray angle-penetration-injection pressure

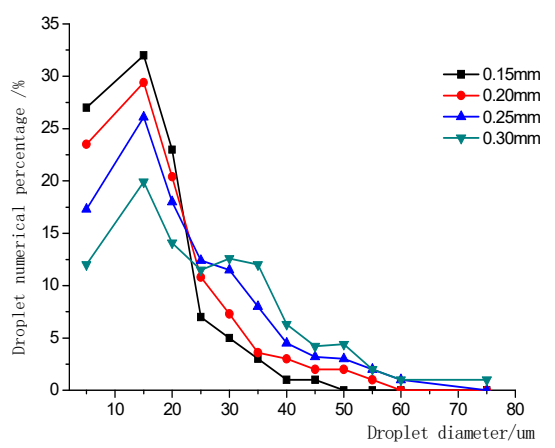

Fig. 5. Droplet of BD30 - nozzle diameter

\subsection{Effect of the mixed fuel atomization nozzle aperture characteristics}

Test conditions were that injection pressure was $90 \mathrm{MPa}$, volume chamber pressure was constant, single injection was the same amount, the nozzle diameter was set to $0.15 \mathrm{~mm}, 0.20 \mathrm{~mm}$, $0.25 \mathrm{~mm}$ or $0.3 \mathrm{~mm}$. Fig. 5 was the spray structural curve of mixed fuel different diameter nozzle at the time of $1.8 \mathrm{~ms}$ after spray beginning. The bigger nozzle diameter was, the greater spray range, while the spray angle was smaller. The main reason was that large nozzle diameter generated less resistance, which made the droplet obtained greater kinetic energy and larger speed, thus distance of droplets conveyed was greater in limited time. Further, the nozzle of fuel cavitation's hardly occurred when the nozzle holes structural parameters $L_{0} / D_{0}$ decreased, the fuel diffusion was restricted to the peripheral beam, and the spray angle was reduced.

The microscopic droplet distributions of BD30 according to different nozzle diameters at $1.8 \mathrm{~ms}$ when injection pressure was $90 \mathrm{MPa}$, constant volume chamber pressure were $4 \mathrm{MPa}$. As can be seen, the smaller nozzle diameter was, the more small-droplet was obtained. To $0.15 \mathrm{~mm}$ nozzle diameter, more than $94 \%$ droplets diameter was less than $30 \mathrm{um}$. The fuel spray effect was found to be well. Conversely, effect became worse. The number of 30 um droplets occupied only $70 \%$ when the nozzle was $0.3 \mathrm{~mm}$ diameter. The reason may be explained by the lower initial kinetic energy obtained slowed the development of fuel-beam and made it had a long time in contact with the surrounding air. 


\section{Conclusions}

1) Atomizing structure of mixed fuel changed with increasing of FAME content. Such as the spray angle decreased and the penetration was gradually increased. The atomization performance is gradually reduced, so the diameter of the microscopic droplet was 17.5 um to main.

2) With the increase of injection pressure, the spray angle decreased and spray range increased. When the FAME content was less than or equal to $30 \%$ of the blended fuel, the rate of spray structure change was smaller than that of higher pressure. The number of small droplets added. Therefore, under the allowance of combustion chamber structure, injection pressure was more conducive to fuel atomization.

3) As the nozzle diameter increased, the spray range is increased, the fog cone angle decreased and the number of large particle droplet increased, which were not conducive to a uniform atomization.

\section{Acknowledgments}

The authors would like to appreciate the financial support from the funds of the Science Technology and Development Plan of Henan Science and Technology Department (Grant number 182102210326) and Research Innovation Team of Mechanical Engineering (Grant number HNACKT-2020-04).

\section{References}

[1] Ma Peng, Liu Huili, Liu Shengyong Experimental study on combustion pressure oscillation of soybean bio diesel oil. International Journal of Agricultural and Biological Engineering, Vol. 9, Issue 6, 2016, p. 156-166.

[2] Ma Qihua, Song Jiantong The characteristics of biodiesel as new automobile energy. Agricultural Equipment and Vehicle Engineering, Vol. 11, 2007, p. 6-10.

[3] Manko I., Shuba Y., Korpach A., Gutarevyc S., Ragulskiene J., Pauliukas A. Measurement of fuel consumption and harmful emissions of cars when using different types of fuel. Journal of Measurements in Engineering, Vol. 8, Issue 4, 2020, p. 182-196.

[4] Ilshat Sharafutdinov, Dicho Stratiev, Ivelina Shishkova, et al. Cold flow properties and oxidation stability of blends of near zero sulfur diesel from Ural crude oil and FAME from different origin. Fuel, Vol. 96, Issue 6, 2012, p. 556-567.

[5] Mohammad Reza Herfatmanesh, Mohammadreza Anbari Attar, Hua Zhao Simultaneous imaging of diesel spray atomisation and evaporation processes in a single-cylinder CR diesel engine. Experimental Thermal and Fluid Science, Vol. 50, Issue 8, 2013, p. 10-20.

[6] Ji Zhang, Tiegang Fang Spray combustion of biodiesel and diesel in a constant volume combustion chamber. SAE, Vol. 4, 2011, p. 15-27.

[7] Yan Chunji, Xie Maozhao, Yin Peihai Mechanisms of breakup and atomization of a viscous liquid jet in a viscous gas. Acta Aerodynamica Sinica, Vol. 22, Issue 4, 2004, p. 422-426.

[8] Pastor J. V., García Oliver J.-M., Nerva J. G., Giménez B. Fuel effect on the liquid-phase penetration of an evaporating spray under transient diesel-like conditions. Fuel, Vol. 90, Issue 11, 2011, p. 3369-3381.

[9] Payri R., Tormos B., Salvador F. J., Araneo L. Spray droplet velocity characterization for convergent nozzles with three different diameters. Fuel, Vol. 87, Issue 15, 2008, p. 3176-3182.

[10] Zhao Luming, He Xu Zheng, Liang, et al. Spray Characteristics of Biodiesel under High Injection Pressure. Transactions of the Chinese Society for Agricultural Machinery, Vol. 43, Issue 9, 2012, p. 6-10.

[11] Li B. Q., Cader T., Schwarzkopf J., Okamoto K., Ramaprian B. Spray angle effect during spray cooling of microelectronics: Experimental measurements and comparison with inverse calculations. Applied Thermal Engineering, Vol. 26, Issue 16, 2006, p. 1788-1795.

[12] Li Tie, Nishida Keiya, Hiroyasu Hiroyuki Droplet size distribution and evaporation characteristics of fuel spray by a swirl type atomizer. Fuel, Vol. 90, Issue 7, 2011, p. 2367-2376. 